\title{
Analysis of Accuracy and Precision of WLAN Position Estimation System based on RSS
}

\author{
Sutiyo $^{1}$, Risanuri Hidayat ${ }^{2}$, I Wayan Mustika ${ }^{3}$, Sunarno $^{4}$ \\ Doct. Student of Department of Electrical Engineering and Information Technology ${ }^{1}$ \\ Department of Electrical Engineering and Information Technology $y^{2,3}$ \\ Department of Nuclear Engineering and Engineering Physics ${ }^{4}$ \\ Universitas Gadjah Mada Yogyakarta, Indonesia ${ }^{1,2,3,4}$
}

\begin{abstract}
The coordinates of the position of a wireless access point are the main goal in the wireless localization technique. In common, outdoor wireless localization techniques use the trilateration method by installing several devices used as anchors, and this makes the cost for installation and maintenance higher. An outdoor wireless localization system that is more efficient, effective, and flexible but still accurate and precise becomes indispensable. This paper proposes a wireless position estimation system based on a received signal strength (RSS) value called WLAN Position Estimation System (WLAN PES) integrating WLAN Distance Estimation System (WLAN DES) with WLAN PES formula. To confirm the accuracy and precision of WLAN PES, this paper focuses on the analysis of WLAN PES testing conducted at ten points in which each measurement point had coordinates and angles that are different from one another. The test point was made to circle the target WLAN access point. The distance of each test point was 1000 meters against the targeted WLAN access point. In each of these test points, the WLAN finder reads $R S S_{\text {fnd }}$. Then, the system calculated the estimated distance value using WLAN DES based on the $R S S_{\text {fnd }}$ value. After the system obtained a distance estimation value, the estimated position value was calculated with the WLAN PES formula. In addition to the distance estimation value, WLAN PES formula required some variables such as latitude and longitude coordinates from the WLAN finder position, and the bearing of the WLAN finder. WLAN PES was found to be capable of determining the estimated position coordinates of a WLAN access point with an accuracy value and precision value of $93.26 \%$ and $98.77 \%$, respectively.
\end{abstract}

Keywords-WLAN position estimation system; WLAN distance estimation system; accuracy and precision wireless localization; efficient and flexible outdoor wireless localization

\section{INTRODUCTION}

Frequency is a limited resource. The use of outdoor 2.4 $\mathrm{GHz}$ WLAN is proliferating for both point-to-point and pointto-multipoint purposes. The limited $2.4 \mathrm{GHz}$ WLAN channel and the increasing use of $2.4 \mathrm{GHz}$ WLAN, especially those installed outdoor, can cause high levels of interference. This, later on, makes the WLAN users to use a range of frequency channels prohibited by government regulations. Hence, monitoring techniques, mitigation techniques, and localization techniques for using WLAN are needed for the optimal and adequate use of frequency resources. Some wireless localization studies in indoor use areas [1]-[3] and use networkbased positioning techniques [4], [5], then several other studies on outdoor wireless localization are based on trilateration or triangulation methods [6], [7].

This method requires several anchors; as a consequence, it becomes less flexible and less efficient in providing devices. In several studies, wireless localization techniques are generally used to localize mobile devices such as smartphones and other tracking devices. Fingerprint method is frequently used in localization and it can be categorized into three types: visual fingerprint, motion fingerprint, and received signal strength (RSS) fingerprint [8]-[10]. Localization with RSS fingerprint method processed based on regression can be accurately used to reduce position estimation errors [11], [12].

In this paper, we discuss the outdoor wireless localization technique for finding the position coordinates of WLAN access points in base transceiver station efficiently and effectively but still accurately and precisely. The position estimation system in this paper is called WLAN Position Estimation System (WLAN PES). This paper focuses on testing the accuracy and precision of WLAN PES.

\section{WLAN DiSTANCE ESTIMATION SYSTEM}

The distance value is significant in the outdoor wireless localization. Before determining the position, a system that can determine the distance estimation is needed. The developed system and part of the position estimation system in this paper are called WLAN Distance Estimation System (WLAN DES). This system integrates outdoor wireless fingerprinting techniques, data analysis systems, and regression analysis. Fig. 1 illustrates the chart of WLAN DES.

The empirical data collection technique in WLAN DES used the outdoor wireless fingerprinting method. The empirical data consists of the received signal strength of the target WLAN access point received by the WLAN finder $\left(R S S_{\text {fnd }}\right)$ and the real distance between the WLAN finder and the WLAN access point $\left(D_{\text {real }}\right)$ [13]. Data from outdoor wireless fingerprinting was analyzed and regressed with a third-degree polynomial to obtain the WLAN DES formula [14].

WLAN DES formula was used to calculate the value of the estimated distance $\left(D_{\text {est }}\right)$ between a WLAN finder and a WLAN access point based on the $R S S_{\text {fnd }}$ value received by the WLAN finder Equation (1) refers a formula to calculate the distance estimation of a WLAN access point in the range 08000 meters. 


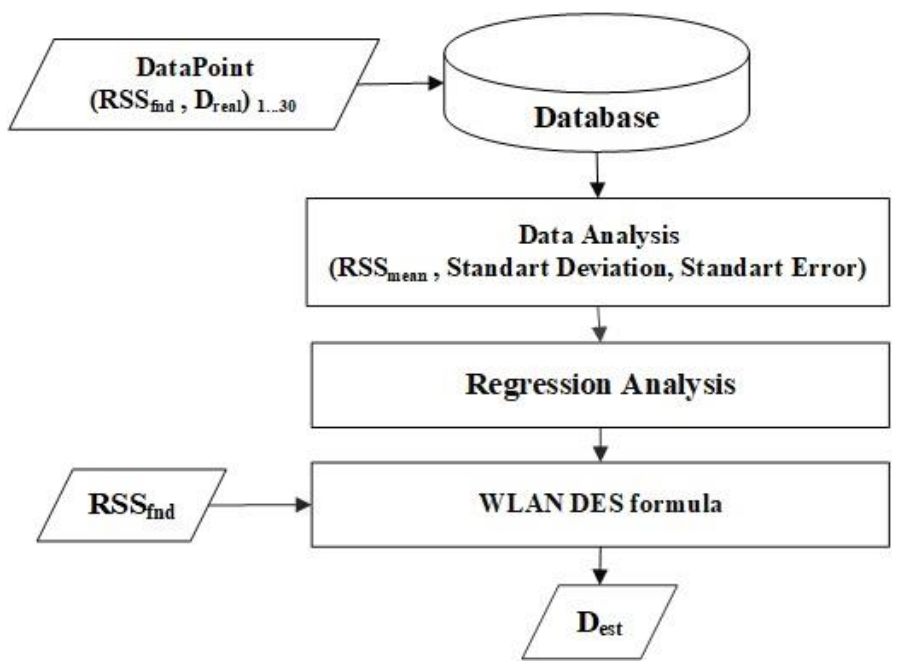

Fig. 1. WLAN Distance Estimation System.

$D_{\text {est }}=-0,0062 R S S_{\text {fnd }}{ }^{3}-$

$0,5455 R R_{\text {fnd }}^{2}-17,95 R S S_{f n d}-132,94$

\section{WLAN POSITION ESTIMATION SYSTEM}

WLAN PES combined the WLAN DES and a geodetic system to determine the coordinates of the position of a target WLAN access point. Fig. 2 shows the algorithm of WLAN PES.

The system was initialized by placing a WLAN finder in a position with specific coordinates. The WLAN finder scanned $R S S_{\text {fnd }}$ from WLAN access points with target frequency channels by rotating the antenna until finding the highest $R S S_{\text {fnd. }}$ The direction of the WLAN finder antenna when getting $R S S_{\text {fnd }}$ at highest value was converted to bearing angle. The highest $R S S_{\text {fnd }}$ value subsequently was converted to distance estimation value using WLAN DES.

WLAN PES consists of 2 main parts:

1) WLAN DES part. This training phase section produces an adaptive WLAN DES formula to calculate the distance estimation value of a WLAN finder against WLAN access point targets.

2) WLAN PES formula also called PEC. The localization phase was used to calculate the estimation of the coordinates of the target WLAN access point position. Three primary data required in the PEC were the estimated distance between the WLAN finder and the WLAN access point target $\left(D_{\text {est }}\right)$, the bearing angle of the WLAN finder $\left(B_{\text {fnd }}\right)$ and the position coordinates of the WLAN finder $\left(P_{\text {fnd }}\right)$.

Fig. 3 presents the WLAN PES algorithm.

Equation (2) is a formula to calculate the estimated latitude of a WLAN access point (Lat $\left.{ }_{a p}\right)$ [15].

$L_{a t}=\operatorname{asin}\left(\sin \left(L_{a t} t_{f n d}\right) \times \cos \left(\frac{D_{e s t}}{R}\right)+\cos \left(L a t_{f n d}\right) \times\right.$
$\left.\sin \left(\frac{D_{e s t}}{R}\right) \times \cos \left(B_{f n d}\right)\right)$

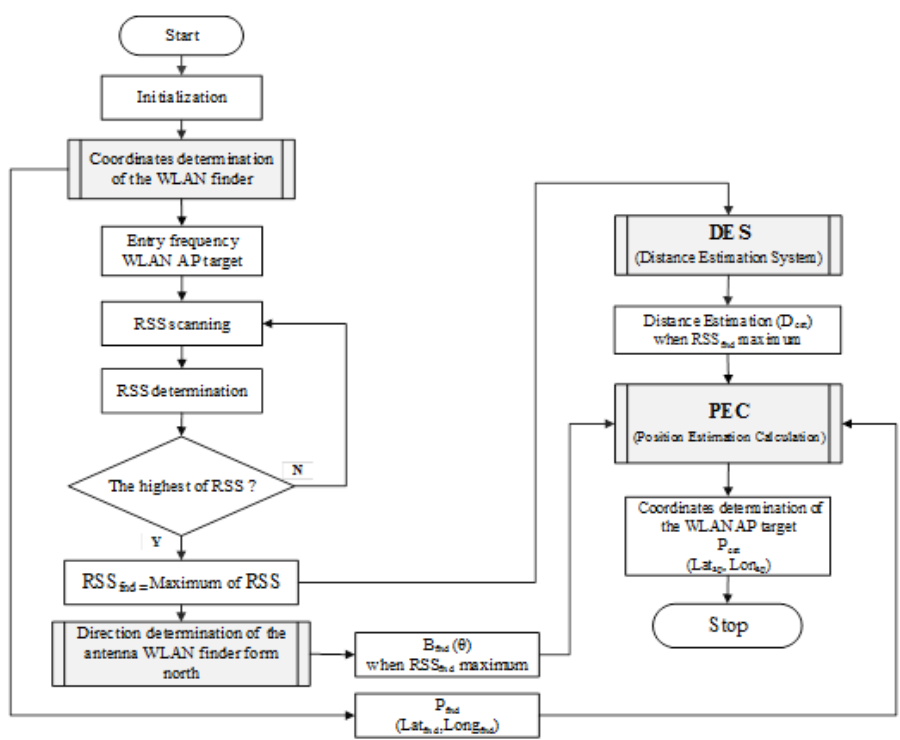

Fig. 2. Algorithm of WLAN Positioning Estimation System.

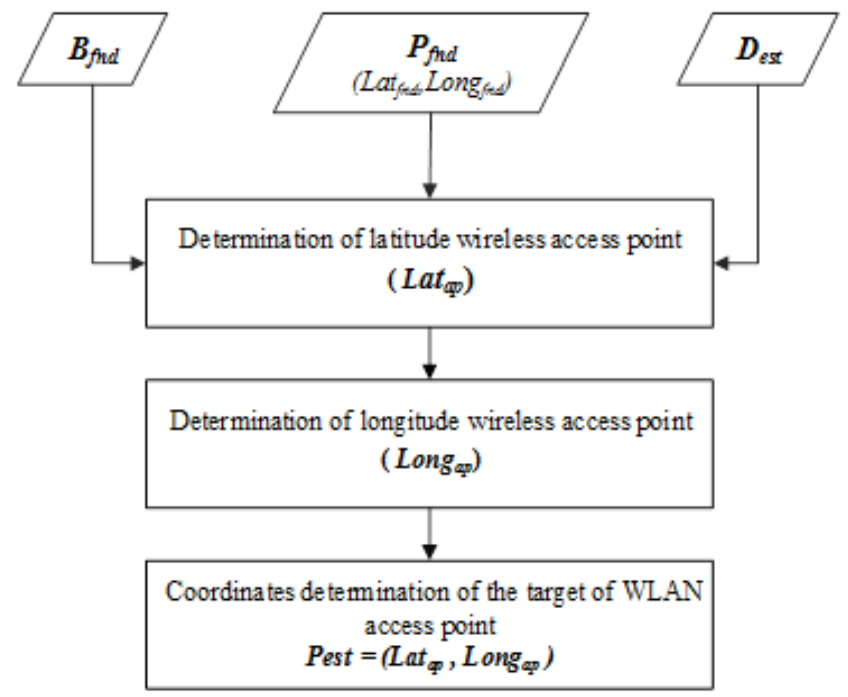

Fig. 3. WLAN PES Formula.

Equation (3) is a formula to calculate the estimated longitude of a WLAN access point. $\left(\operatorname{Lon}_{a p}\right)$.

Lon $_{a p}=$

$\operatorname{Lon}_{f n d}+\operatorname{atan} 2\left(\cos \left(\frac{D_{e s t}}{R}\right)-\sin \left(\operatorname{Lat}_{f n d}\right), \sin \left(B_{f n d}\right) \times\right.$

$\left(\sin \cos \left(D_{\text {est }} \div R\right) \times \cos \left(\right.\right.$ Lat $\left.\left.\left._{f n d}\right)\right)\right)$

Equation (2) and equation (3) were then combined into the WLAN PES formula as in (4).

$P_{\text {est }}=$ Lat $_{a p} ;$ Lon $_{a p}$

\section{RESULTS AND DisCUSSION}

\section{A. WLAN PES Testing}

The WLAN PES testing scheme started by placing a WLAN access point at a location and placing a WLAN finder at ten points in which measurement point had coordinates and 
bearings that were different from one to other. The distance of the WLAN finder to the WLAN access point was 1000 meters, and the position of the WLAN finder was made around the WLAN access point, as shown in Fig. 4.

WLAN PES testing was carried out in the position of WLAN finder-1 to WLAN finder-10, as illustrated in Fig. 4. The coordinates of the WLAN finder position were denoted in the form of $P_{\text {fnd }}\left(L a t_{f n d}, L o n_{f n d}\right)$. There were $30 R S S_{\text {fnd }}$ data from each test point within 30 seconds. To find out the bearing angle of WLAN finder $\left(B_{f n d}\right)$ against the WLAN access point was by scanning the maximum $R S S_{f n d}$ value. The maximum $R S S_{\text {fnd }}$ value indicated that the direction of the WLAN finder antenna was in the direction of the WLAN access point.

Determining the estimation of the WLAN access point position was started by calculating the latitude of the WLAN access point $\left(L a t_{a p}\right)$ and calculating the longitude of the WLAN access point $\left(L_{0 n_{a p}}\right)$. The reference value (earth radius) was around 6,371,000 meters or 6,371 kilometers. The results of WLAN PES testing are informed in Table I.

\section{B. Summary of WLAN PES Testing}

Based on the results of the WLAN PES test as presented in Table I, the mean of distance estimation was performed using the calculation below.

$$
\begin{aligned}
& D_{\text {est-mean }}=\frac{\sum\left(D_{\text {est }-10)}\right)}{\sum f_{\text {Dest }-10}} \\
& D_{\text {est-mean }}=\frac{(1065+1065+\cdots+1065}{10} \\
& D_{\text {est-mean }}=\frac{10720}{10} \\
& D_{\text {est-mean }}=1072
\end{aligned}
$$

The mean of the deviation of distance estimation was then calculated. The deviation of distance estimation is the absolute value of the difference between the estimated distance and the mean of distance estimation. The calculation is presented as follows:

Dev.From mean mean $=\frac{\sum \text { Dev.From mean }-10}{\sum f-10}$

Dev. From mean $_{\text {mean }}=\frac{7+\ldots+7}{10}$
Dev. From mean $_{\text {mean }}=\frac{131}{10}=13.1$

It was continued to calculate the accuracy and precision of the WLAN PES test with the following calculation:

1) The accuracy

$$
\begin{aligned}
& \text { accuracy }=\left(1-\left(\frac{\text { Real distance }-D_{\text {est-mean }}}{D_{\text {est-mean }}}\right)\right) \times 100 \% \\
& \text { accuracy }=\left(1-\frac{72}{1072)}\right) \times 100 \% \\
& \text { accuracy }=93.26 \%
\end{aligned}
$$

\begin{tabular}{|c|c|c|c|c|c|c|c|c|}
\hline \multirow{2}{*}{ No. of Test } & \multirow{2}{*}{$\begin{array}{l}D_{\text {real }} \\
(\mathbf{m})\end{array}$} & \multirow{2}{*}{$\begin{array}{l}R S S_{\text {fnd }} \\
(\mathrm{dBm})\end{array}$} & \multirow{2}{*}{$\begin{array}{l}B_{\text {fnd }} \\
\text { (degree) }\end{array}$} & \multirow{2}{*}{$\begin{array}{l}D_{\text {est }} \\
(\mathbf{m})\end{array}$} & \multicolumn{2}{|l|}{$P_{f n d}$} & \multicolumn{2}{|l|}{$\boldsymbol{P}_{\text {est }}$} \\
\hline & & & & & $\operatorname{Lat}_{\text {fnd }}$ & $\operatorname{Lon}_{\text {fnd }}$ & Lat $_{\text {est }}$ & $\operatorname{Lon}_{\text {fnd }}$ \\
\hline 1 & 1000 & -46 & $78^{\circ}$ & 1065 & $-7.725350^{\circ}$ & $110.679662^{\circ}$ & $-7.723359^{\circ}$ & $110.689116^{\circ}$ \\
\hline 2 & 1000 & -46 & $60^{\circ}$ & 1065 & $-7.727939^{\circ}$ & $110.680686^{\circ}$ & $-7.723150^{\circ}$ & $110.689057^{\circ}$ \\
\hline 3 & 1000 & -46 & $39^{\circ}$ & 1065 & $-7.730397^{\circ}$ & $110.682797^{\circ}$ & $-7.722954^{\circ}$ & $110.688880^{\circ}$ \\
\hline 4 & 1000 & -46 & $356^{\circ}$ & 1065 & $-7.732406^{\circ}$ & $110.689223^{\circ}$ & $-7.721515^{\circ}$ & $110.688454^{\circ}$ \\
\hline 5 & 1000 & -46 & $303^{\circ}$ & 1065 & $-7.728309^{\circ}$ & $110.696197^{\circ}$ & $-7.723727^{\circ}$ & $110.688091^{\circ}$ \\
\hline 6 & 1000 & -46 & $246^{\circ}$ & 1065 & $-7.719831^{\circ}$ & $110.696890^{\circ}$ & $-7.723766^{\circ}$ & $110.688090^{\circ}$ \\
\hline 7 & 1000 & -46 & $239^{\circ}$ & 1065 & $-7.718833^{\circ}$ & $110.696375^{\circ}$ & $-7.723349^{\circ}$ & $110.688790^{\circ}$ \\
\hline 8 & 1000 & -46 & $220^{\circ}$ & 1065 & $-7.716559^{\circ}$ & $110.694419^{\circ}$ & $-7.723896^{\circ}$ & $110.688206^{\circ}$ \\
\hline 9 & 1000 & -47 & $153^{\circ}$ & 1138 & $-7.715387^{\circ}$ & $110.684426^{\circ}$ & $-7.724506^{\circ}$ & $110.689115^{\circ}$ \\
\hline 10 & 1000 & -46 & $138^{\circ}$ & 1065 & $-7.716737^{\circ}$ & $110.682446^{\circ}$ & $-7.723855^{\circ}$ & $110.688913^{\circ}$ \\
\hline
\end{tabular}

2) The precision

$$
\begin{aligned}
& \text { precision }=\left(1-\left(\frac{\text { Dev.From mean }}{\left(D_{\text {est-mean }}\right)}\right)\right) \times 100 \% \\
& \text { precision }=\left(1-\left(\frac{13.1}{1072}\right) \times 100 \%\right. \\
& \text { precision }=98.77 \%
\end{aligned}
$$

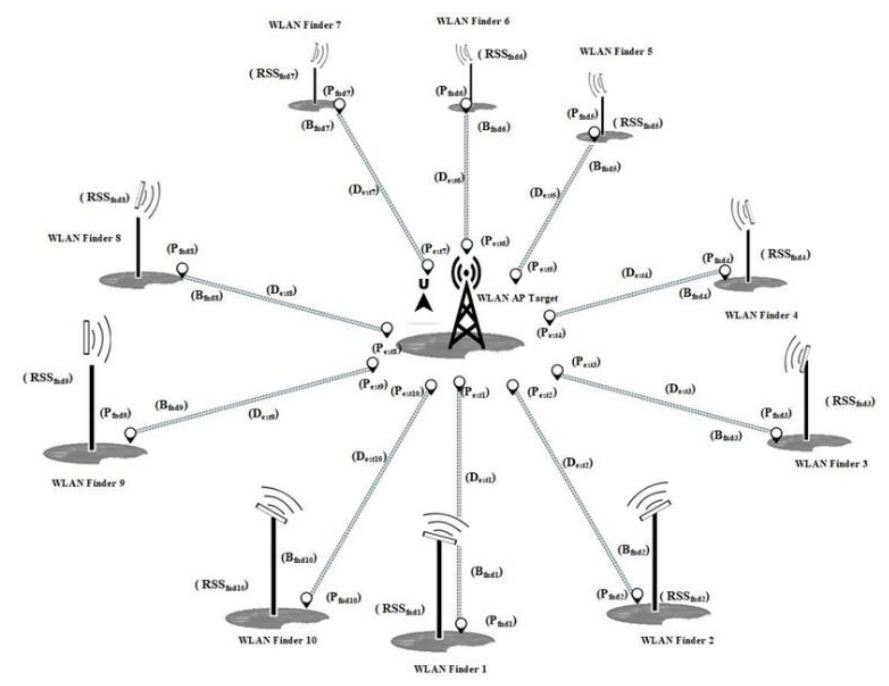

Fig. 4. WLAN PES Testing Scheme.

TABLE. I. RESULTS OF WLAN PES TESTING 


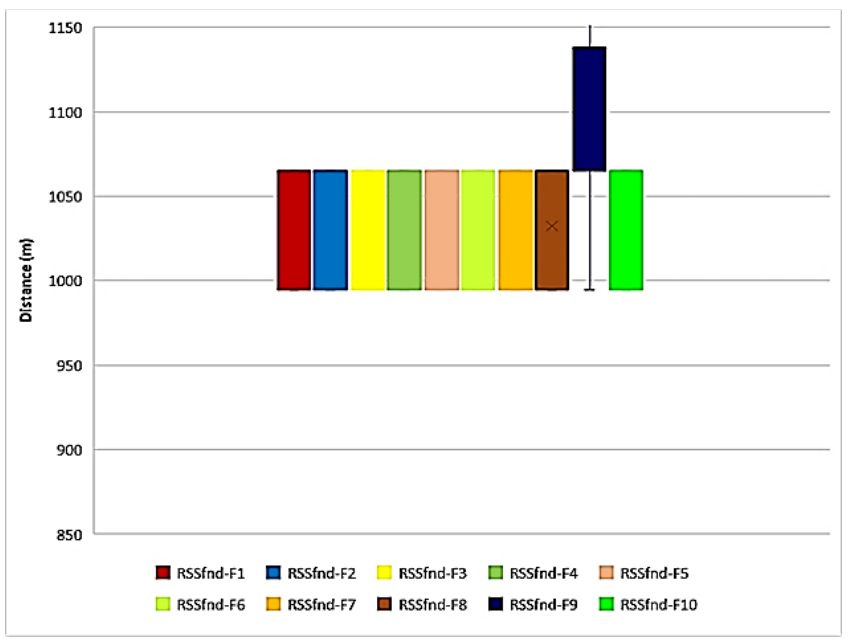

Fig. 5. The Plot Graph of WLAN PES Testing.

The analysis of accuracy and precision from the ten WLAN-PES tests can be visualized into plot graphs, as shown in Fig. 5.

\section{CONCLUSION}

The analysis of WLAN PES testing at ten positions over a distance of 1000 meters resulted in the values of accuracy and precision of $93.26 \%$ and $98.77 \%$, respectively. It then has proven the capability of WLAN PES to be an outdoor wireless localization system that is efficient, effective, flexible, but still accurate and precise.

WLAN PES is more efficient and effective because, in its application, it only requires one RSS value to be able to estimate the coordinates of a WLAN access point position. It is also flexible for use in various areas without a need to install any additional devices. The WLAN position estimation system simulator will be the topic of future research.

\section{ACKNOWLEDGMENTS}

The authors would like to thank the anonymous reviewers for their valuable comments and suggestions to improve the quality of the paper. The authors are also grateful to Department of Electrical Engineering of Universitas Widya Dharma Klaten, Department of Electrical and Information Engineering of Universitas Gadjah Mada Yogyakarta, Nuclear Engineering and Engineering Physics Department of Universitas Gadjah Mada Yogyakarta.

\section{REFERENCES}

[1] C. Chen, Y. Chen, H. Lai, Y. Han, and K. J. R. Liu, "High Accuracy Indoor Localization: A Wifi-Based Approach," ICASSP 2016, pp. 6245-6249, 2016.

[2] S. Wielandt et al., "2.4 GHz Single Anchor Node Indoor Localization System With Angle of Arrival Fingerprinting," 2017 Wirel. Days, pp. 152-154, 2017.

[3] H. X. Jian and W. Hao, "WIFI Indoor Location Optimization Method Based on Position Fingerprint Algorithm,” Proc. - ICSGEA 2017, no. 3, pp. 585-588, 2017.

[4] W. Zhang and X. Yang, "RSSI-Based Node Localization Algorithm For Wireless Sensor Network," J. Chem. Pharm. Res., vol. 6, no. 6, pp. 900905, 2014.

[5] A. Singh, S. Kumar, and O. Kaiwartya, "A Hybrid Localization Algorithm for Wireless Sensor Networks," Procedia Comput. Sci., vol. 57, pp. 1432-1439, 2015.

[6] O. S. Oguejiofor, V. N. Okorogu, A. Adewale, and B. O. Osuesu, "Outdoor Localization System Using RSSI Measurement of Wireless Sensor Network," Int. J. Innov. Technol. Explor. Eng., vol. 2, no. 2, pp. $1-6,2013$.

[7] Y. Liu, Z. Yang, X. Wang, and L. Jian, "Location, Localization, and Localizability,” J. Comput. Sci. Technol., vol. 25, no. 2, pp. 274-297, 2010.

[8] H. Du, C. Zhang, Q. Ye, W. Xu, P. L. Kibenge, and K. Yao, “A Hybrid Outdoor Localization Scheme With High-Position Accuracy and LowPower Consumption,” Eurasip J. Wirel. Commun. Netw., vol. 2018, no. $1,2018$.

[9] S. Xia, Y. Liu, G. Yuan, M. Zhu, and Z. Wang, "Indoor Fingerprint Positioning Based on Wi-Fi: An Overview," ISPRS Int. J. GeoInformation, vol. 6, no. 5, p. 135, 2017.

[10] Q. D. Vo and P. De, "A Survey of Fingerprint-based Outdoor Localization," IEEE Commun. Surv. Tutorials, vol. 18, no. 1, pp. 491506, 2016.

[11] F. Lemic et al., "Regression-Based Estimation of Individual Errors in Fingerprinting Localization," IEEE Access, vol. 7, pp. 33652-33664, 2019.

[12] H. Sallouha, A. Chiumento, and S. Pollin, "Localization in Long-range Ultra Narrow Band IoT Networks using RSSI," 2017 IEEE Int. Conf. Commun., pp. 1-6, 2017.

[13] Sutiyo, R. Hidayat, I. W. Mustika, and Sunarno, "Regression Analysis for Estimated Distance in Fingerprinting-Based WLAN Outdoor Localization System," in 2018 4th International Conference on Science and Technology (ICST), 2018, pp. 557-560.

[14] S. Sutiyo, R. Hidayat, I. W. Mustika, and S. Sunarno, "The Wide Range of Regression Analysis in Distance Estimation System of the Fingerprint-Based Outdoor Wireless Access Point Localization System," Int. J. Eng. Technol., vol. 7, no. 40, pp. 183-186, 2018.

[15] C. Veness, "Calculate Distance, Bearing and More Between Latitude/Longitude Points," Movable Type Ltd, 2019. [Online]. Available: http://www.movable-type.co.uk/scripts/latlong.html. [Accessed: 02-Jan-2019]. 